\title{
La dimensión política de la Junta de Portavoces*
}

\author{
Pilar Cortés Bureta \\ Profesora de Derecho Constitucional \\ Universidad de Zaragoza
}

Recibido: 22.03.2012

Aceptado: 31.05 .2012

Resumen: La junta de portavoces no está prevista ni en la Constitución ni en los Estatutos de Autonomía. Se trata de un órgano cuya existencia, composición, funcionamiento y funciones están reguladas en los distintos reglamentos parlamentarios, tanto en los del Congreso y Senado, como en los de las distintas Asambleas Autonómicas. Sin embargo, de las previsiones reglamentarias, más bien escasas, no se deduce la importancia política de la Junta, ya que se ha convertido en el órgano de dirección política de la correspondiente Cámara, dada la composición de la misma y dadas las funciones que desempeña, especialmente su intervención en la fijación del orden del día.

Palabras clave: Junta de Portavoces, funciones, composición, dirección política, orden del día.

Abstract. The Board of spokepeople is not planned neither in the Constitution nor in the Regional Statutes. It s about an organ which existence, composition, running and functions are regulated in the different parliamentary rules, at both Congress and Senate, and Regional Assemblies. However, from the regulatory forecasts, rather poor, doesn t deduce the politics importance of the Board, as long as it has become in the organ of politics leadership from the respective Chamber, in according to its composition and the functions that it carries out, specially its intervention in fixing the agenda.

Key words: Board of spokepeople, functions, composition, politics leadership, agenda.

Sumario: 1. Introducción.-2. Composición y posición de sus integratantes. - 3. El criterio del voto ponderado (de la unanimidad al consenso).-4. Naturaleza y funciones. 4.1. Fijación del orden del día. 4.2.

* Este trabajo se ha realizado en el marco del grupo de investigación consolidado $\mathrm{S}$ 102, "Nuevas vías de participación política en democracias avanzadas", reconocido por el Gobierno de Aragón en Resolución del Departamento de Ciencia, Tecnología y Universidad, de 15 de abril de 2011. Además, quiero agradecer la colaboración desinteresada aportando experiencia y opiniones cualificadas a D. Nicolás Pérez-Serrano (Letrado del Congreso de los Diputados), Da . Carmen Agueras (Letrada Mayor de las Cortes de Aragón, D. Eloy Suárez (Portavoz del Grupo Parlamentario Popular de las Cortes de Aragón), D. Javier Allúe (Portavoz del Grupo Parlamentario del Partido Aragonés de las Cortes de Aragón), D. Chesus Bernal (Portavoz del Grupo Chunta Aragonesista de las Cortes de Aragón) y a D. Adolfo Barrena (Portavoz del Grupo Parlamentario Mixto). 
Marco de relación, negociación y transacción política. 4.3. Programación de los trabajos de la Cámara.-5. La Junta de Portavoces en las Asambleas Legislativas de las Comunidades Autónomas. 5.1. Previsiones en los Estatutos de Autonomía. 5.2. La Junta de Portavoces en los Reglamentos Parlamentarios Autonómicos. 5.2.1. Composición. 5.2.2. Funcionamiento. 5.2.3. Funciones.

\section{INTRODUCCIÓN}

El actual Parlamento español, como en todos los modernos parlamentos, difícilmente funcionaría sin un órgano como la Junta de Portavoces -JP, a partir de ahora-. Las razones de esta afirmación, respecto al papel fundamental de éste órgano, pretendemos esbozarlas a lo largo de las páginas que siguen.

Haciendo un poco de historia y repasando nuestra tradición constitucional, hacemos un recorrido por nuestras Constituciones históricas, y no encontramos en ellas ni una sola referencia a la figura de la JP. Y tampoco la encontramos en los Reglamentos parlamentarios de nuestra historia constitucional $^{1}$. Por el contrario, no es difícil encontrar en nuestro Derecho Parlamentario, preceptos que se refieran a la obligación del Presidente de decidir y anunciar cuáles van a ser los asuntos a discutir en la sesión siguiente y fijar el orden del día en el salón de sesiones, comunicándoselo al Gobierno, con lo que parece, que las decisiones sobre programación de los trabajos de la Cámara, eran responsabilidad exclusiva de su Presidente ${ }^{2}$.

Esa ausencia de previsiones, no es de extrañar si tenemos en cuenta que tampoco encontramos referencias a los Grupos Parlamentarios y mucho menos a la idea de representación de los partidos políticos en las Cámaras ${ }^{3}$.

Sin duda, la irrupción de los partidos políticos en la vida de las Cámaras, a través de los grupos parlamentarios formados con los diputados y senadores elegidos bajo sus siglas en los procesos electorales, guarda una estrecha relación con la creación de las JP4. Hoy en día, ya nadie se sorprende al leer o al

${ }^{1}$ En el Ordenamiento español, el primer antecedente que nos puede acercar a las Juntas de Portavoces, si bien de forma tímida, lo encontramos en el Reglamento de 1934, al establecer en su art. 12.2 el nombramiento de un representante de los grupos políticos cerca de la Mesa.

${ }^{2}$ Torres Muro, Ignacio, "La Junta de Portavoces. Teoría general y caso español", en $I$ Jornadas de Derecho Parlamentario, Congreso de los Diputados, Madrid, 1984, pág. 303.

${ }^{3}$ No obstante, mantener reuniones informales del Presidente de la Cámara con representantes de las fracciones o de los grupos, fue una práctica habitual en la época monárquica, al menos en su última fase, como refleja Solana, al escribir que el jefe de la minoría socialista "se singularizaba únicamente en las reuniones con el Presidente de la Cámara o en las efectuadas con otros dirigentes de partidos". Solana, Fermín (ed.), Historia Parlamentaria del Socialismo: Julián Besteiro 1918-1920, Madrid, 1975, Tomo I, pág. 355, nota 2.

${ }^{4}$ Oller Sala, Ma Dolores, "La Junta de Portavoces, instrumento político de negociación. Una aproximación al caso español”, Anuario de Derecho Político de la Universidad de Barcelona, $\mathrm{n}^{\circ} 1.1983$, pág. 131. 
escuchar la afirmación de que esos grupos son la expresión de los partidos políticos y que, "los grupos parlamentarios son, a la vez, componentes orgánicos del Parlamento y subunidades de la organización de los partidos, dicho de otro modo, constituyen una penetración de la organización del partido en la estructura del Parlamento"s.

Pues bien, esos grupos cuya relación con los partidos políticos ya es evidente e innegable, se organizan para realizar su trabajo en la Cámara correspondiente $y$, ante la necesidad de relacionarse entre ellos para desarrollar las funciones que tienen atribuidas, nombran unos representantes de sus respectivos grupos, que se van a reunir en forma de juntas para coordinar su actuación. Es entonces cuando se consolidan e institucionalizan las JP.

En España, fueron las Disposiciones de las Cortes de 1977, normas provisionales dictadas por la propia Presidencia de las mismas, las primeras que hacen referencia a los representantes o portavoces de los grupos de la Cámara, si bien, tampoco hicieron referencia a los grupos parlamentarios expresamente. De esa manera, en su art. 21 preveían: "Los Presidentes de cada Cámara podrán reunir siempre que lo estimaran conveniente a los representantes o portavoces de los grupos constituidos en el seno de la misma y además los convocarán, junto con un representante del Gobierno, para deliberar sobre el orden del día de la Cámara y, en general, sobre la ordenación de los debates" (BOC núm. 1583, de 11 de julio de 1977). De la letra de este artículo se deduce que, por una parte, sus reuniones tenían un carácter facultativo porque era facultad del Presidente de la Cámara reunirlos cuando lo estimara conveniente, salvo las convocadas para debatir el orden del día y ordenar los debates, y que, además, sus decisiones, las decisiones que salieran de esas reuniones, no serían vinculantes.

La vigente Constitución española, fiel a aquella tradición constitucional histórica, tampoco regula la JP ${ }^{6}$. Serían los Reglamentos Provisionales del Congreso de los Diputados y del Senado ${ }^{7}$, los que introdujesen e institucionalizasen éste órgano parlamentario en la vida de nuestras Cámaras.

No obstante, de la comparación de ambos textos reglamentarios se deducen diferencias en su regulación. Así, en el Senado, la posición de la Junta de Portavoces era meramente consultiva, ya que se reunía previa convocatoria del Presidente, siendo únicamente obligada para fijar el orden del día, sin que la opinión de la Junta fuese vinculante, porque ese orden del día era fijado definitivamente por el Presidente de la Cámara, de acuerdo con la Mesa (arts. 17, 18 y 61.2 del RpS). Y en el Congreso, sin embargo, se regularon de forma

${ }^{5}$ García Pelayo, Manuel, El Estado de partidos, Madrid, Alianza, 1986, pp. 93-94.

${ }^{6}$ Ninguna de nuestras Constituciones históricas regula la Junta de Portavoces como órgano parlamentario.

${ }^{7}$ Art. 27 del Reglamento Provisional del Congreso de los Diputados de 17 de octubre de 1977 (RpC) y art. 17 del Reglamento Provisional del Senado de 18 de octubre de 1977, BOC núm. 21 de 22 de octubre de 1977 (RpS). 
más amplia las funciones de la Junta. Se configuró como necesaria su conformidad para la fijación del orden del día, se previó la regularidad de sus reuniones y la posibilidad de que fuese convocada a solicitud de la mitad más de uno de los grupos parlamentarios (arts. 27 y 54 del RpC).

En 1982, con la aprobación de los vigentes Reglamentos de ambas Cámaras, la JP se convierte definitivamente en un órgano más de nuestras Cámaras, en ocasiones considerada órgano de dirección de la Cámara, si bien, a nuestro entender, la calificación más correcta sería la de órgano de dirección política, como expondremos más adelante.

La previsión y la creación de la JP en el ordenamiento jurídico español supuso una importante e interesante novedad del Derecho Parlamentario, al incorporar una figura ya conocida por los Ordenamientos de otros países, con distintas denominaciones (Conferencia de Presidentes en Francia e Italia, Conferencia de Decanos en Alemania).

Tal y como está configurada la JP en la normativa reglamentaria, es incuestionable que interviene en la fase de programación del trabajo parlamentario y es un instrumento que facilita y agiliza ese trabajo, pero eso no quiere decir que estemos ante un organismo meramente técnico. Muy al contrario, su principal y fundamental característica es que estamos ante un organismo esencialmente político. Lo que pasa es que la potencial actuación en la vida parlamentaria de cada grupo parlamentario va a depender, en cada momento, de su importancia numérica, de las relaciones entre los distintos partidos presentes en la Cámara y de la unidad política entre Gobierno y mayoría parlamentaria $^{8}$. Y en este punto, nos parece razonable plantearnos el interrogante de que ¿cómo es posible que un órgano tan técnico tenga la importancia que tiene, si tan solo es un instrumento técnico? Pues la respuesta solo puede ser una, y es que su importancia es tal por el carácter político que tiene.

Los reglamentos de Congreso y Senado hacen una relación de las funciones que esta figura tiene atribuidas, pero de esa lectura no es posible deducir el alcance y la importancia política de la JP porque, como ya hemos adelantado, ese carácter de mecanismo político trasciende las previsiones jurídicas.

Si únicamente nos limitamos a contemplar las previsiones jurídicas respecto a sus funciones, comprobaremos, en efecto, que sus poderes no son muy amplios, pero eso contrasta, con que la propia doctrina ha calificado a la JP como "órgano capital", como órgano "central para la vida de la Cámara" o como órgano "de vital importancia" 10 .

${ }^{8}$ Oller Sala, Ma Dolores, "La Junta....”, ob. cit. pp. 132 y 133.

${ }^{9}$ Santaolalla López, F., Crónica parlamentaria I. El Proyecto de Reglamento del Congreso de los Diputados, REDC, nº 3, 1981, pág. 383.

${ }^{10}$ Diario de Sesiones de la Comisión de Reglamento, Congreso de los Diputados, del 20 al 28 de septiembre de 1977. Intervención de Gómez Llorente, pág. 320. 
En la actualidad, sin ninguna duda, la JP es el órgano parlamentario que mejor refleja el predominio de los grupos parlamentarios, ya que en ella se reúnen los portavoces de todos y cada uno de sus grupos, bajo la presidencia del Presidente de la Cámara ${ }^{11}$.

\section{COMPOSICIÓN Y POSICIÓN DE SUS INTEGRATANTES}

La composición de la JP viene determinada en los propios Reglamentos parlamentarios, donde se recoge que son miembros de pleno derecho, los portavoces de los distintos grupos parlamentarios y el Presidente de la Cámara correspondiente, bajo cuya presidencia se reúnen (art. 39.1 RC y art. 43.1 RS). Además de éstos, los Reglamentos prevén la posibilidad de que asistan otros miembros.

Así, el RC establece que a las reuniones de la Junta deben asistir obligatoriamente, al menos un Vicepresidente, uno de los Secretarios de la Cámara y el Secretario General. También pueden asistir suplentes de los portavoces de los grupos y un miembro de cada grupo, sin derecho a voto (art. 39.3 RC).

En el caso del Senado, no se hace referencia a la participación de ningún otro miembro de la Mesa. Pero pueden asistir hasta dos representantes de los grupos territoriales de un mismo grupo parlamentario, designados por su portavoz. Y, cuando se trate de deliberar sobre una materia que afecte a una determinada Comunidad Autónoma, será el propio Presidente el que lo comunique a los portavoces de los grupos en los que haya grupos territoriales para que puedan asistir sus representantes a la reunión (aunque, evidentemente, no tendrán derecho a voto).

La participación del Presidente de la Cámara es habitual en todas las instituciones similares, ya sea en las asambleas legislativas autonómicas o el Parlamento Europeo. En cuanto el Vicepresidente, desempeña su función clásica de sustituir al Presidente en caso de ausencia o de vacante y los Secretarios, su función de redactar actas. En la práctica, a las reuniones de la Junta de Portavoces asiste la Mesa al completo, con todos sus miembros, y lo hacen, además, desde una posición institucional, sin intervenir en los debates. Y eso es así porque, los altos cargos de la Cámara deben defender únicamente los intereses generales de la misma, los cuales, están por encima de los grupos políticos que la integran.

El Secretario General en el Congreso y el Letrado Mayor en el Senado, serán los que presten asistencia a este órgano, desarrollando las habituales funciones de asesoría técnica y redacción de documentos. No intervienen en los debates de los portavoces si no es para cuestiones técnicas.

${ }^{11}$ Contreras Casado, Manuel, "Las Cortes de Aragón”, Derecho Público Aragonés, Zaragoza, El Justicia de Aragón, 2005, pág. 80. 
Esa presencia de altos cargos de la Cámara, nos puede hacer creer que entre la Mesa y la Junta de Portavoces gira toda la actividad Parlamentaria, es decir, que entre ambos órganos deciden la vida y el rumbo de la Cámara, y eso se traduce en el rumbo político del país.

Tanto en el Congreso como en el Senado, a las reuniones de sus respectivas Juntas, podrá asistir un representante del Gobierno, con voz pero sin voto. Para ello, el RC prevé expresamente, que de las reuniones de la Junta se dará cuenta al Gobierno para que, si lo estima oportuno, envíe un representante que podrá estar acompañado por persona que le asista, comunicación que no se exige en el RS (art. 39.2 RC). Esta previsión hay que justificarla en el hecho de que la colaboración entre Ejecutivo y Legislativo redunda en un mejor funcionamiento del sistema en su conjunto, pero todo dependerá de los poderes que se le den al Gobierno en la Junta. Porque lo que no puede ser es que esa intervención limite la autonomía parlamentaria y la independencia de las Cámaras respecto al Gobierno. Y el riesgo de esa limitación se producirá cuando el Gobierno cuente con una sólida mayoría que lo sustente en la Cámara, porque, llegado el caso, podrá conseguir el apoyo de los portavoces de los grupos que le apoyan para imponer su criterio. Pero, en realidad, si el Gobierno cuenta con mayoría en la Cámara, va a conseguir apoyo para cualquiera de sus iniciativas, con lo cual, da lo mismo que imponga su criterio en la Junta como que lo imponga en la propia Cámara. En definitiva, los grupos que apoyan al Gobierno lo van a hacer en cualquiera de los dos ámbitos.

Por otra parte, tampoco parece muy sensato excluir al Gobierno de las reuniones de la Junta, defendiendo esa autonomía de la Cámara, porque podría conducirnos a una peligrosa falta de contactos entre el Parlamento y aquél y a una diversidad en la dirección política de cada uno de los poderes, que redundaría en una dispersión de políticas y de rumbo para el país. Es de esperar que una coordinación Parlamento-Ejecutivo redunde en un mejor funcionamiento de las instituciones con los beneficios que eso puede reportar al Estado en su conjunto. No debemos olvidar que el Gobierno necesita al Ejecutivo para sacar sus iniciativas legislativas adelante y, sobre todo, necesita su confianza para seguir gobernando ${ }^{12}$.

En cualquier caso, la asistencia de un miembro del Gobierno parece fundamental a la hora de articular el trabajo de la Cámara, conciliando el papel de los Grupos Parlamentarios, como titulares de la función legislativa y como encargados del control al Gobierno, y las aspiraciones del binomio Gobiernomayoría, intentando sacar adelante su programa de gobierno y siendo motor de la actividad legislativa.

${ }^{12}$ Una absoluta discrepancia entre Gobierno-Ejecutivo podría llevar a la pérdida de la confianza de aquél y, por consiguiente a una moción de censura o a una disolución de las Cámaras. 
No hemos de perder de vista el carácter de la participación de tal representante, que es un mero asistente no un integrante de la Junta, el cual se puede hacer oír pero, llegado el caso, no puede votar ${ }^{13}$. Su función será exponer y transmitir las opiniones gubernamentales, si lo estima necesario, y participar en los debates. Ni que decir tiene que lo de no poder votar tampoco es tan importante porque se supone que el Gobierno cuenta con el voto de los Grupos que lo apoyan o que le dieron su apoyo en la investidura, con lo cual, en caso de votación, contaría con su voto favorable. Los reglamentos no dicen nada respecto al rango del miembro del Gobierno que puede asistir, con lo cual, en principio, podrá asistir cualquier miembro del Gobierno o cualquier persona apoderada por éste. Seguramente decidir quién vaya a asistir a cada Junta, será una decisión marcada por las cuestiones a tratar y por el interés que el Gobierno tenga en ellas. Es una cuestión que queda en manos del Ejecutivo y entra dentro de su potestad de organizarse y, puede enviar un representante, en cuyo caso decidirá el nivel de tal representante, o puede no enviarlo, puesto que los reglamentos son flexibles en ese sentido, y el Gobierno no está obligado a enviarlo, ni se le puede obligar a ello ${ }^{14}$.

A pesar de lo dicho, la asistencia de un representante del Gobierno a la Junta puede que no sea tan importante para coordinar la actividad parlamentaria con la función gubernamental, porque es una vía demasiado formalizada, $\mathrm{y}$ hay otras vías informales u otros mecanismos para hacerlo.

Lo que no contempla ninguno de los dos Reglamentos, ni el del Congreso ni el del Senado, es que puedan asistir los Presidentes de las Comisiones. Y tampoco está prevista la intervención directa de esas Juntas en la programación del trabajo de las Comisiones, únicamente en la programación del Pleno (en realidad sólo en la del Pleno del Congreso, que es el que necesita el acuerdo de la Junta para fijar el orden del día porque en el del Senado, la Junta simplemente será oída).

En ese sentido, ningún reglamento de ninguna asamblea autonómica, prevé la asistencia de los Presidentes de las distintas Comisiones, cuando regulan la composición de sus respectivas JP. Y lo mismo en el reglamento del Parlamento Europeo ${ }^{15}$, cuya Conferencia de Presidentes está integrada por el Presidente del Parlamento y por los presidentes de los grupos políticos (art. 24 RPE), si bien, allí está también prevista la existencia de una Conferencia de Presidentes de Comisión (art. $27 \mathrm{RPE}$ ), previsión que no se da en los reglamentos de Congreso y Senado, ni en los de las asambleas autonómicas.

${ }^{13}$ La propia letra de las previsiones reglamentarias ya hace esta diferencia. El art. 43.1 RS dice que "La Junta de Portavoces estará integrada..." y el art. 43.2 RS "A las reuniones de este órgano ... podrán asistir un representante del Gobierno...".

${ }^{14}$ Art. 39.2 RC De las reuniones de la Junta se dará cuenta al Gobierno para que envie, si lo estima oportuno...".

${ }^{15}$ Reglamento del Parlamento Europeo, 16 ${ }^{\text {a }}$ edición, 15 de mayo de 2010 (última actualización, 10 de marzo de 2011) (RPE). 
Sobre la conveniencia o no de que los Presidentes de las Comisiones asistan a las reuniones de la Junta podemos apuntar y esgrimir argumentos a favor y argumentos en contra, como exponemos a continuación.

Si tenemos en cuenta el carácter de instrumento técnico que le hemos atribuido a la Junta, agilizando y facilitando el trabajo parlamentario, y teniendo en cuenta que debe ser oída para fijar el calendario de sesiones y para la fijación del orden del día (en el Congreso se exige su acuerdo), la ausencia de los Presidentes de las Comisiones en la Junta y la falta de una intervención directa de la misma en la programación del trabajo de las Comisiones, no encuentra una fácil explicación y, además, es un hecho que "podría influir de forma negativa en los cometidos de programación del trabajo parlamentario encomendado a la Junta de Portavoces y, en general, en toda la programación de la actividad parlamentaria"16.

Sin duda, en el trabajo parlamentario tiene tanta importancia, o más, la labor que se lleva a cabo en Comisiones, algunas de ellas de especial relevancia porque pueden incluso aprobar leyes, como la desarrollada por el Pleno. Por eso, la programación de ese trabajo podría ser global, para el conjunto de los órganos parlamentarios. Los Reglamentos del Congreso y del Senado no prevén una programación global de toda la actividad parlamentaria, sino que regulan, por un lado la programación de los trabajos del Pleno y, por otro, los de las Comisiones. En ese sentido, la Junta de cada una de las Cámaras (junto con la Mesa) parece el lugar más adecuado para elaborar una programación de forma coordinada del trabajo de esos órganos, de todos ellos, y ahí es donde parece razonable y aconsejable que los Presidentes de las Comisiones puedan acudir a las reuniones de la Junta.

Por el contrario, la verdad es que las Comisiones son órganos de trabajo subordinados al Pleno, como lo demuestra el hecho de que en el Senado, su Presidente puede convocarlas y fijar su orden del día y, en cualquier caso, su orden del día será fijado teniendo en cuenta el programa de trabajos de la Cámara; y en el Congreso su orden del día será fijado por la propia Mesa de la Comisión pero de acuerdo con el Presidente de la Cámara y teniendo en cuenta el calendario fijado por la Mesa ( art. 67.2 RC).

Como ya hemos dicho, elaborar el orden del día no es una tarea propiamente técnica, sino que tiene un fuerte componente político, y esos intereses técnicos están mucho mejor representados por los miembros de la Mesa que asisten a las sesiones de la Junta. En realidad, la JP no tiene la posición preeminente en la elaboración del orden del día, ya que son las Mesas de las dos Cámaras las que participan activamente en esa labor, siendo el órgano que más se ocupa de este aspecto de la organización. Quizá por ello, la presencia de los Presidentes de las Comisiones sea más defendible en las Mesas.

${ }^{16}$ Viver Pi-Sunyer, Carles, "Naturaleza jurídica, organizació i funcionament del Parlament de Catalunya”, Administración Pública, núm. 4, junio-julio, 1981, pág. 117. 
Por otro lado, la Junta representa a los Grupos parlamentarios, y no parece que los Presidentes de las Comisiones tengan ahí cabida. Además en España, las presidencias de Comisiones no se reparten, sino que pertenecen, mayoritariamente, al grupo mayoritario, con lo cual, su presencia, aunque sea con voz pero sin voto, podría hacer peligrar el mínimo equilibrio mayoríasminorías que debe reinar en los debates.

En la práctica, la presidencia de las Cámaras sí que mantiene reuniones con los Presidentes de las Comisiones, de manera intermitente, pero no para adoptar acuerdos sino para informarles de lo decidido en otros órganos, para unificar las prácticas parlamentarias y para que cumplan el calendario de trabajo.

Pero la razón de ser de la JP es, sin duda, reunir a los portavoces de los grupos parlamentarios, que actúan como representantes y siguiendo las consignas de los mismos. Son los que representan los intereses de los partidos políticos organizados en la Cámara y son los únicos que tienen derecho a voto en la Junta. La designación del portavoz y de los que eventualmente, puedan sustituirle, debe constar en el propio acto de constitución de los grupos, como exigen los Reglamentos de ambas Cámaras (art. $24.2 \mathrm{RC}$ y $28.2 \mathrm{RS})^{17}$. Y en el Congreso, cabe la posibilidad de que tanto los portavoces como los suplentes puedan estar acompañados por un miembro de su grupo, aunque sin derecho a voto (art. 39.3 RC), cosa que en la práctica se da muy a menudo porque de esa manera es más de una persona la que está al tanto de las decisiones que en la Junta de adoptan y, además, permite que exista más de una voz por grupo.

Sin embargo, eso no quiere decir que entre el grupo y su portavoz haya una relación de mandato imperativo, ya que el portavoz en la Junta actúa de manera libre, como estima oportuno en cada momento, aunque, de hecho siga las instrucciones de sus representados, o del partido político al que representa. Y tampoco supone una delegación de voto de los representados el portavoz, porque aunque el portavoz, llegado el caso de una votación, y en función del criterio del voto ponderado, tiene tantos votos como miembros de su grupo, en realidad el parlamentario de base no delega sus poderes en el portavoz, simplemente se trata de una "ficción", que no va más allá de la Junta. Llegado el Pleno, cada uno de los parlamentarios, votará según su propio criterio, aunque éste, en base a la disciplina de voto, habitualmente sea coincidente con el

${ }^{17}$ Aún así se pueden dar situaciones de incorporaciones de representantes no previstos, como destaca Rubio Llorente: "la composición (de la Junta) ...ofrece, sin embargo, en cuanto a los nombres concretos que de ella forman parte, una cierta imprecisión, pues, junto a designaciones de los portavoces realizadas mediante comunicación escrita a la Presidencia de la Cámara, ha habido otras realizadas apud acta mediante la manifestación ante la Junta, en tal o cual sesión, de la decisión de incorporarse a la misma en representación de determinado Grupo". Introducción a Cortes Generales, Congreso, Memoria Legislatura 1977-79, Madrid, 1979, pág. 12. 
de su portavoz ${ }^{18}$. En ese sentido, la JP no es más que la cristalización de esa disciplina ${ }^{19}$.

Asiste a la Junta, un portavoz de cada grupo, de manera que la composición no es proporcional al número de escaños, sino igualitaria para todos los grupos. Todos y cada uno de ellos están representados por un solo portavoz, incluido el Grupo Mixto, aunque en el estén agrupados representantes de varias y diversas formaciones políticas. De esta manera, la Junta, que tiene una dimensión media, es el foro perfecto para debatir y tomar decisiones, con más facilidad que si hubiese varios miembros de cada grupo. Además, los grupos minoritarios se colocan casi en la misma posición que los grupos mayoritarios, lo que es importante a la hora de defender sus derechos, aunque sepan que, en caso de votación, su fuerza sigue siendo minoritaria.

Destacable es el hecho de que son los portavoces de los grupos parlamentarios, porque son en torno a los cuales se estructura la Cámara, y no los portavoces de las formaciones políticas con presencia en la Cámara. De no ser así, el Grupo Mixto, o los grupos parlamentarios formados por una coalición de varias fuerzas políticas, deberían tener varios portavoces, tantos como formaciones políticas tuvieran representadas.

\section{EL CRITERIO DEL VOTO PONDERADO (DE LA UNANIMIDAD AL CONSENSO)}

Pocas son las previsiones jurídicas respecto al funcionamiento interno de la Junta de Portavoces.

La Junta se reúne por convocatoria del Presidente de la Cámara (art. 39.1 RC y art. 43.1 RS). En el Senado, el Presidente tiene el monopolio de la convocatoria, pero en el Congreso, el Presidente comparte esa potestad de convocatoria, porque puede ser, además, a instancia de dos grupos parlamentarios o de la quinta parte de los miembros de la Cámara, posibilidades que no están previstas en el RS. Lo que no está previsto en ninguno de los Reglamentos, es que el Gobierno pueda solicitar esa convocatoria, ni tampoco ningún diputado o senador a título individual.

Nada prevén los Reglamentos sobre el funcionamiento interno de la Junta ni sobre la regularidad de las reuniones. En la práctica esas reuniones se vienen celebrando previamente a la celebración de una sesión plenaria, pero también se celebran reuniones ocasionales de las que no se levanta acta ${ }^{20}$.

${ }^{18}$ Torres Muro, Ignacio, “La Junta de...”, ob. cit., pág. 314.

19 Torres Muro, Ignacio, Los órganos de..., ob. cit., pág. 240.

${ }^{20}$ En este punto, nadie considera reuniones de la Junta de Portavoces, las ocasiones en las que, en medio de un Pleno, surge una cuestión concreta que el Presidente decide consultar con los portavoces. En esos casos, el Presidente hace un receso en el Pleno y consulta, pero de esa consulta ni se levanta acta ni se considera, como decíamos, reunión de la Junta de Portavoces propiamente dicha. 
Una cuestión de capital importancia en la propia configuración y en el funcionamiento de la Junta es la forma de tomar decisiones. El RS, por su parte, no hace referencia a este punto, mientras que en el Congreso se adoptarán siempre por votación y en función del criterio del voto ponderado (art. 39.4 RC). No obstante, en la práctica, las decisiones de la Junta del Senado, también se toman por medio del procedimiento del voto ponderado ${ }^{21}$.

El criterio del voto ponderado supone que cada portavoz tendrá tantos votos como escaños tiene en la Cámara su grupo parlamentario, lo que, obviamente, asegura una posición predominante del grupo o de la coalición mayoritaria, en detrimento de los grupos minoritarios.

Si el criterio fuese la unanimidad, los grupos se verían obligados a buscar el acuerdo y se daría la oportunidad de introducir asuntos propuestos por los grupos minoritarios. En este sentido, ha sido la doctrina italiana la que ha señalado que la toma de decisiones por unanimidad, debería ser la principal característica de la Conferencia de Presidentes (denominación italiana de la Junta de Portavoces) $)^{22}$.

Entendemos, sin embargo, que la obligatoriedad de la unanimidad, podría acabar colapsando la propia JP, haciendo imposible tomar cualquier decisión, por sencilla que fuese. Además, si todos los órganos de la Cámara-Comisiones, Ponencias, Diputación Permanente- tienen una formación proporcional a la del Pleno y cuando tienen que tomar una decisión se hace también bajo el criterio del voto ponderado, la JP, que es uno más de esos órganos, no tiene razón de ser diferente.

Como excepción, el art. 67.4 del RC, exige la unanimidad para incluir un de terminado asunto en el orden del día, aunque no haya cumplido los trámites reglamentarios necesarios. La explicación de tal exigencia está en el hecho de que permite incumplir una de las reglas básicas de todo procedimiento, como es que los asuntos que pasan al Pleno, han de haber cumplido todos los trámites.

La verdad es que, a pesar de la previsión del voto ponderado, en la práctica diaria, hemos de apuntar que raramente se vota en Junta de Portavoces, al menos en el Congreso de los Diputados ${ }^{23}$. Puede parecer una paradoja pero, no exigiéndose unanimidad para la toma de decisiones, los portavoces buscan el consenso o al menos, el apoyo suficiente para no recurrir a una votación.

${ }^{21}$ La misma previsión del voto ponderado aparece en los reglamentos de las asambleas autonómicas. Y en el Parlamento Europeo, la primera previsión de su Reglamento es que "la Conferencia de Presidentes tratará de alcanzar un consenso sobre los asuntos que se le sometan", y cuando eso falle "se procederá a una votación ponderada de acuerdo con el número de diputados de cada grupo político" (art. $24 \mathrm{RPE}$ ).

${ }^{22}$ S. Tosi, Diritto Parlamentare, Giuffré Editore, Milano, 1974, pp. 210 y ss.

${ }^{23}$ Por el contrario, en alguna asamblea autonómica, como es el caso de las Cortes de Aragón, el recurso a la votación es prácticamente constante. 
Por último, las sesiones de la JP son a puerta cerrada, y sus actas no se publican. Quizá en el hecho de no publicarlas no haya una intención de secretismo, pero lo cierto es que es así, y donde no hay obligación legal o reglamentaria de publicarlas, no se hace ${ }^{24}$.

\section{NATURALEZA Y FUNCIONES}

Del tenor literal de los Reglamentos parlamentarios, no parece deducirse que las Juntas de Portavoces tengan una especial importancia, a juzgar por las funciones que tienen atribuidas. Eso plantea la evidencia de que a la Junta no se le da una importancia proporcional a la importancia que tienen los grupos parlamentarios en nuestro sistema, como vertebradores de la vida de las Cámaras.

Sin embargo, la práctica y la costumbre nos han demostrado que sus poderes son mayores que los que derivan de la letra de los preceptos reglamen$\operatorname{tarios}^{25}$. Y es que, cuando se trata de estudiar la previsión jurídica de una serie de competencias o funciones, limitarse a los textos legales puede ser un error porque el reparto de esas competencias que hacen los reglamentos de las Cámaras, entre los distintos órganos no es base suficiente para calibrar la importancia de los mismos ${ }^{26}$.

Y ese es el caso de la Junta de Portavoces, que más que por las funciones que tiene atribuidas por vía reglamentaria, vale por la gran influencia política que tiene, ya que representa las opiniones de los grupos parlamentarios, que son los que integran la Cámara y los que protagonizan su actividad. Por eso se ha dicho de ella que "a pesar de las escasas atribuciones que los reglamentos confieren a las Juntas, éstas son en la práctica -sobre todo la del Congreso- los órganos decisorios en los casos conflictivos de auténtica importancia política" ${ }^{27}$ y que "llegaron a constituir los verdaderos órganos de decisión y en casos de auténtica importancia política, las funciones reales que asumieron fueron decisivas" 28 .

Antes de pasar a examinar algunas de las funciones de la JP, vamos a detenernos un momento en analizar la naturaleza de éste órgano.

${ }^{24}$ Los reglamentos de las asambleas autonómicas tampoco suelen prever la publicación de las actas de la JP. La única excepción la encontramos en el Reglamento de la Asamblea de Extremadura, cuyo art. 66 establece su carácter público.

${ }^{25}$ Ya sucedió así en la legislatura constituyente, como señala Ramírez Jiménez, Manuel, “Teoría y práctica del grupo parlamentario", REP, núm. 11, 1979.

${ }^{26}$ Torres Muro, I., Los órganos de gobierno de las Cámaras legislativas. Presidente, Mesa y Junta de portavoces en la Derecho parlamentario español, Congreso de los Diputados, Madrid, 1987, pág. 267.

${ }^{27}$ García Molrillo, en Esteban y López Guerra (dir.), El régimen constitucional español 2, Barcelona, 1982, pág. 98.

${ }^{28}$ Oller Sala, Mª Dolores, “La Junta...”, ob. cit., en nota 2, pág. 151. 
Por una parte estamos ante un órgano deliberante, del que serían miembros todos los que reglamentariamente pueden asistir a sus reuniones, pero, por otra parte, también se trata de un órgano de adopción de acuerdos, del que sólo serían miembros los portavoces de los grupos parlamentarios, que son los que tienen derecho a voto ${ }^{29}$.

De manera que, en función de cuál sea la función de la JP, ésta aparece como un órgano deliberante o como un órgano decisorio. Y, además, según actúe como órgano deliberante o como órgano decisorio, tendrá unos miembros u otros o, dicho de otro modo, sus miembros tendrán distinta posición. Es decir, en una JP deliberante, se consideran miembros, a todos aquellos que reglamentariamente pueden asistir, ya que únicamente se trata de debatir, discutir, intercambiar opiniones o planteamientos, incluso negociar; mientras que en una JP decisoria, en la que hay que tomar una decisión imputable a dicho órgano, o en la que se plantea una votación, únicamente se consideran miembros, los portavoces de los grupos parlamentarios.

Y si esta diferenciación se plantea respecto al papel de los miembros que integran la JP, los Reglamentos parlamentarios utilizan distintas expresiones que nos pueden plantear interrogantes sobre el verdadero papel de la propia Junta. Porque las previsiones reglamentarias utilizan expresiones como "con el parecer favorable de la Junta", "de acuerdo con la Junta" o la Junta "será oída", que son expresiones distintas y con un significado aparentemente diferente, respecto a su intervención. En ese sentido, planteamos dos cuestiones:

$1^{\mathrm{o}}$ ¿Es preceptiva la consulta a la Junta? No nos plantea dudas la respuesta porque si la Junta debe ser oída o se necesita su parecer o su acuerdo, es incuestionable que la consulta es preceptiva. Cosa distinta es lo que nos lleva a la segunda cuestión.

$2^{\circ}$ ¿Son vinculantes los acuerdos de la Junta? Aquí la respuesta ya no es tan sencilla ni tan clara, sino que habrá que detenerse en la literalidad de cada precepto reglamentario. Unas veces, el Reglamento simplemente prevé que ha de ser escuchada, con lo cual, puede interpretarse que hay obligación de escucharla pero su decisión no es vinculante; y, otras veces, cuando el Reglamento exige el acuerdo de la Junta, hemos de entender que la consulta, además de ser preceptiva, el acuerdo que adopte será vinculante.

Los actuales Reglamentos contienen una regulación distinta para la Junta en sus respectivas Cámaras. En términos generales, en el Congreso se configura como un órgano decisor en ciertos casos, mientras que en el Senado se presenta como un órgano meramente consultivo ${ }^{30}$.

${ }^{29}$ Solé Tura, J. y Aparicio, M. A., Las Cortes Generales en el sistema constitucional español, Tecnos, Madrid, 1984, pág. 138.

${ }^{30}$ Quizá es diferente configuración obedezca a una menor estructuración partidista del Senado, y así se reflejó en su Reglamento. Oller Sala, Ma. D., "Los órganos de ..., ob. cit., pág. 106. 
En la mayoría de los artículos de los Reglamentos parlamentarios, no se exige el acuerdo de la Junta sino sólo que debe ser oída, de manera que, en la mayoría de los casos son la Mesa o el Presidente, o ambos conjuntamente, los que toman las decisiones.

Pero, si esas son las previsiones reglamentarias, en la práctica política parece difícil imaginar a la Mesa o al Presidente de una Cámara, tomando una decisión absolutamente en contra de la Junta de Portavoces, ya que son los verdaderos protagonistas de la vida política de las Cámaras. En cuanto a la Mesa, parece difícil que pueda tomar una decisión en contra de la JP, porque sus miembros son también integrantes de esos grupos parlamentarios, de manera que a la hora de decidir, no creo que fuesen a provocar un enfrentamiento. Respecto al Presidente de la Cámara, realmente puede tomar una decisión en contra de la JP pero, supondría enfrentarse abiertamente con el conjunto de la Cámara, con el conjunto de los representantes de los ciudadanos y, además de la gran dificultad de mantener esa decisión, llegado el caso, la dificultad de llevarla a cabo. Por otro lado, buscar el consenso con la Junta de Portavoces es, tanto para la Mesa como para el Presidente, una forma más de legitimar sus decisiones. Sin duda, cualquier decisión, o actuación, que salga de la Cámara y vaya con el apoyo del Presidente, de la Mesa y de la JP, va a ser mucho mejor recibida, asumida, percibida, o simplemente valorada, por parte de la opinión pública, porque da una imagen de cohesión y consenso que, en algunos asuntos, los ciudadanos reclamamos.

De esta manera, pasamos a analizar algunas de las funciones de la Junta de Portavoces que, a nuestro entender, más trascendencia política tienen.

\subsection{Fijación del orden del día}

En la actualidad, tal y como establece el art. $75 \mathrm{CE}$, nuestras Cámaras funcionan en Pleno y en Comisiones. Las Comisiones realizan el trabajo preparatorio para el Pleno, gran escenario de la actividad política. Cuando un asunto llega al Pleno, ya se ha trabajado, discutido, consensuado, lo que sea según el caso, pues el Pleno no es más que la puesta en escena de lo ya decidido antes. Sin duda, se trata de una escenificación importante, porque va a ser lo que los ciudadanos contemplen y porque van a ser las noticias políticas que van a recoger los medios de comunicación al día siguiente, pero sobre todo es importante porque son las decisiones que van a marcar el rumbo de la vida política y, a partir de ella, en el ámbito social, económico, etc...

Por esos motivos, fijar el orden del día, decidir qué se va a representar en cada sesión plenaria, tiene una importancia vital en la Cámara. Porque es donde nuestras formaciones van a fijar posiciones, donde le van a desvelar al ciudadano cuál es realmente su postura sobre los distintos asuntos que se traten.

Pues bien, decidir esos puntos, es lo que hace la Junta de Portavoces con el Presidente de la Cámara. Con lo cual, a primera vista ya deducimos que la 
voluntad política de la Cámara se encargan de formarla el Presidente con la JP.

Aparentemente, la fijación del orden del día es un instrumento excepcionalmente importante para organizar y programar el trabajo parlamentario. Sin embargo, a medida que el trabajo de las Asambleas ha ido aumentando y, sobre todo, en la medida en la que en ellas se integran grupos políticos de ideologías dispares, incluso radicalmente opuestas, representando los distintos sectores de la sociedad, ese instrumento, que parece meramente técnico, se ha convertido en un instrumento político.

La fijación del orden del día, debería ser un simple mecanismo para conseguir el orden en los trabajos de la Cámara, pero como eso supone decidir los asuntos que se van a tratar en el Pleno, esa fijación se ha convertido en un asunto de especial importancia y relevancia en el que todos están interesados en participar. Porque hay que decidir los asuntos que van y los que no, y todo ello atendiendo a criterios estrictamente políticos, y si me apuran puramente partidistas, algunas veces. De esa manera, determinar el contenido del orden del día es determinar el contenido de la actividad parlamentaria, pero también de la actividad política.

Además, como en la Junta de Portavoces están representados los grupos de la Cámara por sus líderes, la Junta se convierte en un importante centro de poder dentro de la misma ${ }^{31}$, sencillamente porque el Presidente o la Mesa consulta con los portavoces, pide sus opiniones, sus puntos de vista y llega a acuerdos con ellos.

Realmente, la JP se ha convertido en el órgano que lleva la verdadera dirección política de la Cámara, pero no debemos perder de vista el papel de Pleno y las Comisiones, que no deben convertirse en meros órganos refrendantes de las decisiones que tome la $\mathrm{JP}^{32}$.

En muchas ocasiones, la JP sólo ha de ser consultada y su consulta no es vinculante, pero, como ya hemos adelantado anteriormente, resulta difícil imaginar que el Presidente o la Mesa adopten una decisión en contra de la opinión de la JP. En primer lugar, por la propia legitimación del Presidente y de la Mesa, porque cualquier decisión que adopten estará mucho más reforzada si lleva el apoyo de la JP y, en segundo lugar, por razones de funcionalidad, llevar a cabo cualquier decisión en contra de los Grupos Parlamentarios puede desembocar en una importante disfuncionalidad de la propia Cámara.

A pesar del importante trabajo de la Junta en la programación del trabajo parlamentario, la Junta no es, estrictamente, un "órgano de la programación" parlamentaria ${ }^{33}$, puesto que esas funciones no las desempeña en exclusiva,

${ }^{31}$ Torres Muro, Ignacio, “La Junta de ...”, ob. cit., pág. 298.

${ }^{32}$ Oller Sala, Ma Dolores, "La Junta ...”, ob. cit., pág. 155.

${ }^{33}$ Ese es el caso italiano y así la denomina Manzella, A., Il Parlamento, Il Mulino, Bolonia, 1977, pág. 102. 
sino junto con el Presidente o la Mesa y, por otro lado, ni interviene en la programación del trabajo ni en la fijación del orden del día de las Comisiones.

En el Congreso, el orden del día del Pleno es fijado por el Presidente de la Cámara, con el acuerdo de la Junta, de donde se deduce que su consulta, no sólo es preceptiva sino que, como se requiere su acuerdo, además es vinculante (art. 67.1 RC). Mientras tanto, en el Senado, la Junta simplemente será oída para fijarlo, de donde se deduce que su consulta es preceptiva, pero su acuerdo no es necesario, con lo cual, no es vinculante (art. 44. b R).

En este punto el Gobierno tiene una posibilidad de intervención porque, en el Congreso, puede pedir que en una sesión concreta se incluya un asunto con carácter prioritario, siempre que haya cumplido los trámites reglamentarios, que hagan que esté en condiciones para ser incluido en el orden del día. Aun sin haberse cumplido esos trámites, la Junta, a iniciativa del Gobierno o de un grupo parlamentario, puede acordar que un asunto sea incluido en el orden del día. En cualquier caso, el Gobierno no puede imponer prioritariamente un asunto, sólo puede "pedir" su inclusión en el orden del día (art. 67. 3 y 4 RC). En el Senado, en cambio, el representante del Gobierno, podrá incluir un solo asunto con carácter prioritario en el orden del día (art. 71. $1 \mathrm{RS}$ ).

Aunque ya hemos adelantado que la JP no interviene en la fijación del orden del día de las Comisiones, no podemos dejar de hacer referencia a la Comisión General de las Comunidades Autónomas del Senado, porque presenta una especialidad respecto a las demás Comisiones. En este caso, para fijar su orden del día, para determinar el orden y la duración de las intervenciones y para ordenar el debate posterior, se requiere la audiencia de los Portavoces de los grupos en la Comisión. Nótese que se hace referencia a los portavoces de los grupos en Comisión, pero no se hace referencia a la JP como órgano, sino sólo a los portavoces de los grupos que estén representados en la Comisión.

\subsection{Marco de relación, negociación y transacción política}

La JP constituye, junto con las Ponencias, uno de los marcos perfectos para la negociación y la transacción política. La razón de esta afirmación es bien sencilla. Es un foro reducido, cuyas actas no se publican, donde no hay público, y donde los integrantes pueden dialogar con tranquilidad. Nuestros representantes necesitan de esa negociación y si no disponen de medios o foros para realizarla, los buscarán, y entonces les acusaremos de utilizar medios extraparlamentarios. No obstante, si se me permite, no nos parece que ésa sea una apreciación correcta, ya que sería más correcto entender que, en esos casos, serán medios extraórganos, aunque intraparlamentarios, es decir, medios que se encuentran dentro del Parlamento, aunque fuera de los órganos establecidos.

En ese sentido, la JP sirve de marco de relación, en primer lugar, de los diferentes grupos parlamentarios donde, a través de sus portavoces, pueden 
discutir sobre los asuntos que se planteen y donde, seguramente, será más fácil llegar a acuerdos entre ellos.

En segundo lugar, sirve de punto de contacto entre los órganos de Gobierno de la Cámara (Presidente y Mesa) y los Grupos Parlamentarios, que no son más que la trascripción parlamentaria de los partidos políticos. De esa manera, se asegura la participación conjunta para adoptar cualquier decisión.

$\mathrm{Y}$ es, en tercer lugar, un foro donde se relacionan con el Gobierno y, más en concreto, donde se produce el encuentro entre el binomio Gobierno-mayoría y minoría. Y ese foro puede ser el adecuado para el diálogo, para la negociación y para la transacción política, entre mayoría y minorías y entre Gobierno-mayoría y la oposición. Sin duda el margen de actuación de la JP será menor, por no decir nulo, si nos encontramos en un caso de mayoría absoluta para un Grupo Parlamentario, o si el Gobierno cuenta con el apoyo de los Grupos suficientes para que le den esa mayoría, porque si se plantea una votación, se impondrá su criterio. La lógica nos pone de manifiesto que el debate y la búsqueda del consenso entre el mayor número de Grupos Parlamentarios será mayor cuanto más repartidos estén los escaños entre dichos Grupos, es decir, cuando el Gobierno necesite el apoyo de más de un Grupo para sacar adelante sus pretensiones.

En definitiva, en el seno de la Junta se llevan a cabo negociaciones fundamentales para el buen funcionamiento de las Cámaras y el secreto que rodea sus sesiones puede ser el adecuado para lograr acuerdos. Sin duda, dada su composición, es el órgano idóneo para realizar funciones integradoras y de consenso político ${ }^{34}$.

\subsection{Programación de los trabajos de la Cámara}

En el Congreso, la Junta será oída por la Mesa para programar las líneas generales de actuación de la Cámara, para fijar el calendario de actividades del Pleno y de las Comisiones para cada período de sesiones y coordinar los trabajos de sus distintos órganos (art. 31.1.6 $6^{\circ} \mathrm{RC}$ ). Pero fijar un calendario a largo plazo es muy difícil, salvo que se sea consciente de que no se va a cumplir, porque la actividad de las Cortes, o de una Cámara en particular, es muy difícil de concretar, por pura lógica, porque hay muchas variables que pueden cambiar y muchos asuntos que pueden surgir en cualquier momento, alterando así esas previsiones. Por eso, se pueden fijar las grandes líneas de la actividad parlamentaria pero nada más. El hecho de que sea oída, quiere decir que únicamente es necesaria su consulta, pero que el resultado de ésta no vincula la decisión de la Mesa.

${ }^{34}$ Oller Sala, Ma . D., "Los órganos de dirección de las Cámaras: Presidente, Mesa y Junta de Portavoces", Revista de la Facultad de Derecho de la Universidad Complutense, núm. 10, 1986, pág. 109. 


\section{LA JUNTA DE PORTAVOCES EN LAS ASAMBLEAS LEGISLATI- VAS DE LAS COMUNIDADES AUTÓNOMAS}

\subsection{Previsiones en los Estatutos de Autonomía}

Las Asambleas legislativas de las Comunidades Autónomas funcionan de manera similar a como lo hacen las Cámaras de las Cortes Generales. Al igual que Congreso y Senado, todas cuentan con un reglamento que regula todo lo relativo a su composición, organización y funcionamiento. Y, como no podía ser de otro modo, también prevén la existencia de una Junta de Portavoces.

De cómo regulan sus respectivas Juntas de Portavoces los Reglamentos de las distintas asambleas legislativas Autonómicas, vamos a dar cuenta en las líneas que siguen.

Para empezar, al igual que la Constitución, en la mayoría de los Estatutos de Autonomía no se prevé la existencia de la Junta como órgano de la asamblea autonómica. Hemos dicho bien, en la mayoría de los Estatutos, porque en algunos sí que está recogido este órgano, si bien lo hacen de manera distinta, como veremos.

Así, el Estatuto de Cataluña, en su art. 59.2, relativo a la organización y funcionamiento, establece que el Reglamento del Parlamento regulará, entre otras cosas "las atribuciones de la Junta de Portavoces" ${ }^{35}$, con lo cual, da por hecho la existencia de la misma. En el Estatuto de Autonomía de la Comunidad de Madrid, encontramos dos previsiones, una en el art. 12.d donde, en términos similares a la del estatuto catalán, se prevé que será el Reglamento de la Asamblea el que determinará "las funciones de la Junta de Portavoces"; y otra, con una clara referencia a su composición y a quién ha de presidirla, en el art. 13.2, cuando establece que "Los Diputados de la Asamblea se constituirán en Grupos Parlamentarios, cuyos portavoces integrarán la Junta de Portavoces, que se reunirá bajo la presidencia del Presidente de la Asamblea"36.

Previsión distinta es la que encontramos en el Estatuto de Autonomía de Cantabria, que sólo hace referencia a la Junta para destacar una de las ocasiones en las que la misma debe ser oída, y es en el art. 13 cuando establece que "El Presidente del Parlamento coordina los trabajos del Parlamento y de sus Comisiones y dirige los debates. La Mesa asiste al Presidente en sus funciones y establece el orden del día, oída la Junta de Portavoces" ${ }^{37}$. Se trata de una de las funciones principales de la Junta, la determinación del orden del día, pero en este caso su participación, siendo preceptiva no es vinculante, ya que únicamente ha de ser oída, pero no se exige su acuerdo.

${ }^{35}$ Ley Orgánica 6/2006, de 19 de julio, de reforma del Estatuto de Autonomía de Cataluña. BOE n ${ }^{\circ} 172,20$ de julio de 2006.

${ }^{36}$ Ley Orgánica 3/1983, de 25 de febrero, del Estatuto de Autonomía de la Comunidad de Madrid. BOE ${ }^{\circ}$ 51, de 1 de marzo de 1983.

${ }^{37}$ Ley Orgánica 11/1988, de 30 de diciembre, de reforma de la Ley Orgánica 8/1981, de 30 de diciembre, del Estatuto de Autonomía de Cantabria. BOE n⿳ 313 , de 31 de diciembre de 1998. 
Y, por último, en el Estatuto de Autonomía de Extremadura, no encontramos una referencia directa a la Junta, pero sí a los que son sus integrantes, a los portavoces, cuando en el art. 31 establece que "El Presidente de la Asamblea de Extremadura, previa consulta a los Portavoces designados por los Grupos Parlamentarios, en el plazo de quince días desde la constitución del Parlamento, propondrá un candidato a la Presidencia de la Junta (...)"38. Se trata de una ronda de consultas similar a la que hace el Rey para proponer un candidato a la Presidencia del Gobierno, consultando con los representantes de las formaciones políticas con representación parlamentaria (art. $99 \mathrm{CE}$ ).

Si estas eran las escasas previsiones de los Estatutos de Autonomía, en los Reglamentos parlamentarios autonómicos, encontramos una completa previsión y regulación de la JP en cada una de las Asambleas autonómicas.

\subsection{La Junta de Portavoces en los Reglamentos Parlamentarios Autonó- micos}

\subsubsection{Composición}

La regulación de la Junta de Portavoces que hacen los distintos Reglamentos autonómicos es bastante similar, como exponemos a continuación ${ }^{39}$.

${ }^{38}$ Ley Orgánica 12/1999, de 6 de mayo, de reforma de la Ley Orgánica 1/1983, de 25 de febrero, del Estatuto de Autonomía de Extremadura. BOE nº 109, de 7 de mayo de 1999.

${ }^{39}$ Referencia de los Reglamentos autonómicos a los que nos vamos a referir:

- Reglamento del Parlamento de Andalucía (RPA), de 21 de septiembre de 2005 $\left(\right.$ BOPA n $^{\circ} 285,23$ de septiembre de 2005);

- Reglamento de las Cortes de Aragón (RCA), de 26 de junio de 1997 (BOCA n ${ }^{\circ}$ 124, 30 de junio de 1997);

- Reglamento de la Junta General del Principado de Asturias (RJGPA) (BOPA n ${ }^{\circ}$ 16,18 de julio de 1997, última modificación en BOPA $n^{\circ} 135,11$ de junio de 2008);

- Reglamento del Parlamento de Canarias (RPCAN) de 17 de abril de 1991 (última modificación BOCAN no 218, 30 de julio de 2009);

- Reglamento del Parlamento de Cantabria (RPC), de 26 de marzo de 2007 (BOC $\mathrm{n}^{\circ}$ 90, 10 de mayo de 2007);

- Reglamento de las Cortes de Castilla-La Mancha (RCCLM), de 16 de octubre de 1997 (BOCCLM n 133, 16 de octubre de 1997, última modificación en BOCCLM n ${ }^{\circ}$ 164, 11 de diciembre de 2009);

- Reglamento de las Cortes de Castilla y León (RCCL), de 11 de mayo de 2005 (BOCCL n ${ }^{\circ}$ 179/6, 29 de julio de 2005);

- Reglamento del Parlamento de Cataluña (RPCAT), de 22 de diciembre de 2005 $\left(\mathrm{BOE} \mathrm{n}^{\circ} 38,14\right.$ de febrero de 2006);

- Reglamento de la Asamblea de Extremadura (RAE), de 19 de junio de 2008 (BOE ${ }^{\circ} 131,8$ de julio de 2008);

- Reglamento del Parlamento de Galicia (RPG), de 1 de septiembre de 1983 (BOPG $n^{\circ} 150,1$ de septiembre de 1983, última modificación en BOG n ${ }^{\circ} 3,4$ de enero de 1995); 
En cuanto a su composición, todos esos Reglamento prevén, en primer lugar, que la Junta esté compuesta por los portavoces de los Grupos Parlamentarios, reunidos bajo de presidencia del Presidente del Parlamento, de la Asamblea o de la Junta. Esos portavoces, podrán estar acompañados de un miembro de su Grupo Parlamentario. En cuanto a los suplentes de los portavoces, algunos Reglamentos establecen que pueden asistir y otros no dicen nada al respecto. Y en el caso del miembro del Grupo que puede acompañar al suplente del portavoz, caso de que éste no asista, no tendrá, ni siquiera derecho a la palabra (RCA).

Además, deben asistir a las reuniones, un Vicepresidente, un Secretarios de la Cámara y el Letrado Mayor o, en su defecto, un letrado de la Cámara.

En algunos casos está previsto que puedan asistir los demás miembros de la Mesa, así como los Presidentes de las Comisiones o cualquier Diputado de la Cámara, para oírles sobre asuntos de su competencia o respecto a iniciativas en tramitación.

En general, también está previsto que de las reuniones de la Junta se de cuenta al Gobierno, para que envíe, si lo estime oportuno, un miembro o alto cargo en quien éste delegue, que podrá estar acompañado por la persona que lo asista. Lo que ocurre es que, en algunos Reglamento se prevé que se informe al Gobierno, con carácter general de todas las reuniones de la Junta y en otros, únicamente cuando el Presidente entienda que se van a tratar asuntos que afecten o sean de su interés (RCA). El RACCE especifica que sea el propio Consejo de Gobierno el que, por iniciativa propia o a instancia de la Junta, encomiende a un Consejero la comparecencia ente la Junta a fin de aclarar alguna cuestión o ser interrogado sobre algún extremo que figure en el orden del día.

- Reglamento del Parlamento de las Islas Baleares (RPIB), de 23 de junio de 1986 (BOPB $n^{\circ} 23,22$ de julio de 1986, modificación en BOPB $n^{\circ}$ 47,13 de abril de 1991);

- Reglamento de la Asamblea de Madrid (RAM), de 30 de enero de 1997 (BOAM $\mathrm{n}^{\circ} 82,31$ de enero de 1997);

- Reglamento de la Asamblea Regional de Murcia (RARM), de 14 de abril de 1988, última reforma de 13 de junio de 2002; Reglamento del Parlamento de Navarra (RPN), de 8 de octubre de 2007 (BON n 138, 5 de noviembre de 2007);

- Reglamento del Parlamento de La Rioja (RPLR), de 10 de abril de 2001 (BOPLR n ${ }^{\circ}$ 95, 18 de abril de 2001);

- Reglamento de las Cortes Valencianas (RCV), de 28 de diciembre de 2006;

- Reglamento del Parlamento Vasco (RPV), de 11 de febrero de 1983 ( BOPV n ${ }^{\circ}$ 025, 18 de febrero de 1983, modificaciones en BOPV $n^{\circ}$ 187, 29 de diciembre de 2008 y n $^{\circ} 29,16$ de octubre de 2009);

- Reglamento de la Asamblea de la Ciudad de Ceuta (RACCE), (BOCCE 22 de enero de 2007);

- Reglamento de la Asamblea de la Ciudad de Melilla (RACM), de 7 de septiembre de 1995 (modificación en BOME nº 9, 12 de marzo de 2004). 


\subsubsection{Funcionamiento}

Respecto a su funcionamiento, la convocatoria la hace el Presidente, a iniciativa propia, a petición de uno o dos Grupos Parlamentarios, según los casos, y además, a petición de la décima parte de los miembros de la Cámara, en unos casos, y en otros de la quinta parte de esos miembros. El caso del RCA, establece que en estos dos últimos casos, el Presidente tiene un plazo no superior a ocho días para realizar la convocatoria, introduciendo, además, en el orden del día el asunto o asuntos propuestos por aquéllos. O, el RJGPA, que establece que en esa petición ha de haber un máximo de cuatro asuntos, que deberán incluirse en el orden del día. O el RAE que establece que el Presidente deberá convocar la Junta en un plazo máximo de cuarenta y ocho horas, a petición motivada con propuesta de orden del día de un grupo parlamentario, limitando el número de veces que cada grupo pueda formalizar esa petición a dos veces por período se sesiones. O el RARM, según el cual, la reunión deberá celebrarse en los cinco días hábiles a la solicitud. O el RPN que exige que la reunión se celebre en el plazo máximo de diez días hábiles. O el RPLR, que deberá celebrarse en un plazo no superior a cuatro días desde que se formule la petición. Y el RACM, en un plazo no superior a cuatro días desde que se formule la petición.

El RAE también prevé que la Junta sea convocada por el Presidente, de acuerdo con la Mesa, a petición motivada del Gobierno autonómico.

Sólo el RAE prevé, expresamente, que la convocatoria debe hacerse con al menos veinticuatro horas de antelación, especificando el orden del día. Y el RACCE con dos días hábiles de antelación comunicando el orden del día a tratar.

En algunos casos se fija el quórum que ha de tener la Junta para constituirse válidamente, como es el caso del RJGPA, que exige que concurran la mitad más uno de los Grupos Parlamentarios siempre que representen, a su vez, la mayoría absoluta de los miembros de la Cámara. O el RAE, que para quedar válidamente constituida, en primera convocatoria exige la presencia de los portavoces o suplentes de todos los grupos de la Cámara, pero en segunda convocatoria exige sólo la presencia de los portavoces que representen, al menos la mitad más uno de los Diputados de la Cámara, entendiendo que no estará válidamente constituida si no está presente el presidente, al menos un Vicepresidente de la Mesa, un secretario y el Letrado Mayor o letrado que lo sustituya. O el RPV, que exige la mitad más uno de los grupos que, a su vez, representen la mayoría absoluta de los miembros de la Cámara.

Lo que todos los Reglamentos prevén, es la periodicidad mínima con la que se ha de reunir la JP durante el período de sesiones, que generalmente es quincenalmente $\mathrm{o}$, en algún caso mensualmente.

También aquí, las decisiones de las diferentes Juntas se adoptarán atendiendo al criterio de voto ponderado.

En ese sentido, el RPC contiene una previsión específica respecto al Grupo Mixto, y es que, el portavoz de tal Grupo, deberá acreditar el sentido 
del voto de cada uno de los diputados a partir del momento en que así lo solicite por escrito ante la Mesa de la Cámara, un diputado de dicho Grupo. Y el RPN, que establece que el portavoz del Grupo Mixto tendrá tantos votos como miembros del Grupo le hayan otorgado la representación que deberá acreditar por escrito. $\mathrm{O}$ el RACCE que prevé que en el caso del Grupo Mixto pueda asistir un representante de cada fuerza política con respaldo electoral.

Algunos Reglamentos prevén expresamente la necesidad de levantar acta de las sesiones de la Junta por parte del Letrado Mayor o letrado que le sustituya, supervisada y autorizada por el Secretario que asista, con el visto bueno del Presidente. Y, en algunos casos, también se establece un plazo para que los componentes puedan realizar reclamaciones.

Pero únicamente el RAE establece que las actas sean públicas. Y más aún, prevé que las sesiones de la Junta sean grabadas, si bien sólo serán transcritas cuando se requiera previamente por alguno de sus miembros. Ese texto transcrito ya sólo estará a disposición de la Junta.

El RACCE diferencia entre sesiones ordinarias y extraordinarias de la Junta, dejando la calificación de ordinarias para las sesiones a las que hemos hecho referencia en toda la exposición y calificando como extraordinarias aquellas que no necesitan convocatoria previa ni comunicación del orden del día, siendo necesaria únicamente la efectiva concurrencia de todos los portavoces.

\subsubsection{Funciones}

La regulación de las funciones de la Junta es bastante similar en los distintos Reglamentos autonómicos. En unos casos encontramos un listado más o menos amplio, que recoge una serie de funciones, y en otros caso, a falta de ese listado, las funciones están dispersas a lo largo del articulado.

Lo que debemos destacar es que, en la mayoría de los Reglamentos, se trata de unas funciones en las que se exige la previa audiencia a la Junta pero no su acuerdo, con lo cual, se trata de una intervención preceptiva, es decir, es obligatorio escuchar a la Junta, pero no vinculante, lo que quiere decir, que las actuaciones se pueden llevar a cabo sin el acuerdo o la conformidad de la Junta. Sólo el RAE y el RAM, distinguen, expresamente, entre asuntos en los que se requiere el acuerdo de la Junta y asuntos en los que debe ser oída.

Las funciones más repetidas en los Reglamentos parlamentarios autonómicos son las siguientes:

- fijar los criterios que contribuyan a ordenar y facilitar los debates y tareas del Parlamento,

- concretar las fechas en que hayan de comenzar y terminar los períodos de sesiones de la Cámara,

- decidir la Comisión competente para conocer de los proyectos y proposiciones de ley,

- fijar el número de miembros de cada grupo parlamentarios que deberá formar las Comisiones y Diputación Permanente, 
- asignar los escaños en el salón de sesiones a los diferentes grupos parlamentarios, $\mathrm{y}$

- establecer el calendario de actividades de las Comisiones.

En un sentido más concreto, el RPLR prevé que la Junta pueda aprobar declaraciones institucionales a iniciativa del Presidente, de dos grupos parlamentarios o de la quinta parte de los miembros de la Cámara. Y el RPV y el RAE establece que la Junta podrá aprobar esas declaraciones institucionales por unanimidad. Y el RACCE según el cual, la Junta podrá aprobar declaraciones institucionales a iniciativa de su Presidente o un grupo político válidamente constituido. El RJGPA prevé que la Junta pueda acordar, por unanimidad, declaraciones de carácter urgente.

El RPC, el RCCLM, el RCCL, el RAE, el RARM, el RPN es el que hace referencia explícita a la fijación del orden del día como una función de la Junta, y en algunos no sólo el orden del día del Pleno sino también el de las Comisiones.

El RACCE tiene una enumeración de las funciones curiosa y distinta a los demás Reglamentos, estableciendo que la Junta:

- tiene funciones sobre las materias referidas a las relaciones entre los grupos políticos y de éstos con los diferentes órganos corporativos, para su mejor funcionamiento;

- y es un órgano consultivo del Presidente de la Asamblea, en todas aquellas materias que afecten al desarrollo de las sesiones plenarias, adopción de medidas disciplinarias contra uno o varios Diputados y en todas aquellas relativas a la representación protocolaria de la Corporación y otras que afecten a la gestión pública. 